\title{
EDITORIAL
}

\section{IL-17 in spondyloarthritis: is the T-party over?}

\author{
Nataliya Yeremenko and Dominique Baeten* \\ See related research by Appel et al., http://arthritis-research.com/content/13/3/R95
}

\begin{abstract}
The past decade has witnessed significant progress in revealing an important role for IL-17 in the pathogenesis of several immune-mediated inflammatory diseases. Recent studies have provided new insights into the cellular source of IL-17, originally identified as the signature cytokine of a distinct CD4 ${ }^{+}$T-cell subset known as Th17. Accumulating evidence suggests that the majority of the IL-17 released in inflammatory arthritis is produced by innate immune cells rather than T cells. Understanding molecular mechanisms behind these early innate immune responses will be the key to designing rational therapies targeting these important inflammatory pathways.
\end{abstract}

\section{Introduction: the IL-23/IL-17 axis in spondyloarthritis} In the present issue of Arthritis Research \& Therapy, Heiner Appel and colleagues from Berlin present an important histological study on IL-17-producing cells in spondyloarthritis (SpA) [1]. The IL-23/IL-17 axis has become a major focus of SpA research based on three key observations. Firstly, the ankylosing spondylitis subset of $\mathrm{SpA}$ is associated with genetic polymorphisms of the IL-23 receptor - the protective R381Q gene variant has recently been demonstrated to impair Th17 responses [2,3]. Secondly, the unfolded protein response - a cellular stress programme that can be initiated by HLA-B27 misfolding - strongly increases the production of IL-23 [4]. Thirdly, a recent proof-of-concept trial with an anti-IL-17A monoclonal antibody showing good efficacy in active ankylosing spondylitis provided the first direct evidence that IL-17 plays an important role in SpA pathogenesis [5].

\section{Identification of IL-17-producing cells}

The IL-23/IL-17 axis was originally described in T-cell biology, where IL-23 is a crucial factor in the so-called

*Correspondence: D.I.baeten@amc.uva.nl

Clinical Immunology and Rheumatology, G4-212, Academic Medical Center/ University of Amsterdam, Meibergdreef 9, 1105 AZ Amsterdam, The Netherlands
Th17 response. Th17 cells have been demonstrated to play a pathogenic role in many experimental autoimmune diseases. In human SpA, several studies enumerating Th17 cells in SpA have yielded partially conflicting results - but a recent report convincingly demonstrated an increased presence and IL-17 production of KIR3DL2 ${ }^{+}$ $\mathrm{T}$ cells responsive to HLA-B27 homodimers in blood and synovial fluid [6]. Before postulating that these cells are the major IL-17 producers in SpA, however, one should consider the fact that many other cell types besides canonical Th17 cells express the IL-23 receptor and respond to IL- 23 by producing IL- 17 .

Based on the original demonstration that IL-23 is able to induce IL-17 production in RAG-deficient mice that lack both B cells and T cells [7], there is now also ample evidence in humans that IL-17 is produced by $\gamma \delta \mathrm{T}$ cells, mast cells, neutrophils, and innate lymphoid cells between others. This concept urged translational researchers to reassess the cellular source of IL-17 in the primary target tissues of a various diseases. Several seminal studies have identified noncanonical IL-17-producing cells in tissue inflammation, including mast cells in rheumatoid synovitis and psoriasis and innate lymphoid cells in inflammatory bowel disease [8-10]. It is in this context that Appel and colleagues made the crucial observation that innate immune cells rather than canonical $\mathrm{T}$ cells express IL-17 in axial spondyloarthritis. Their extensive histological analysis of zygoapophyseal joints clearly demonstrates that $\mathrm{CD} 15^{+}$neutrophils and myeloperoxidasepositive myeloid cells, but not classical $\mathrm{T}$ cells, are the major cellular sources of IL-17 in the inflamed bone marrow. These data corroborate with emerging evidence that mast cells and neutrophils, but not $\mathrm{T}$ cells, are also the major cellular source of IL-17 in peripheral SpA. Taken together, these studies emphasise the relevance of direct analysis of affected tissues and postulate a role for innate IL-17-producing cells in SpA.

\section{Production of IL-17-related cytokines}

The observations of Appel and colleagues urge us to revisit the pathobiology of the IL-23/IL-17 axis in SpA. Firstly, we will have to investigate which cytokines and transcription factors are responsible for this innate IL-17 response. Although it is tempting to propose a role for 
IL-23 and RAR-related orphan receptor C based on the Th17 biology, this remains to be formally demonstrated and would not suffice to explain why SpA displays an innate rather than acquired IL-17 response.

Secondly, it will be crucial to determine which cytokines are exactly produced by these innate IL-17producing cells. This includes better characterisation of the IL-17 isotypes, as the reagents used in Appel and colleagues' study and most other reports do not allow one to formally discriminate IL-17A from IL-17F. A related cytokine of major interest is IL-22 as its production is also IL-23 dependent and closely related to IL-17 in $\mathrm{T}$ cells. IL-22 provides a unique signal directionality from the immune system to the stromal tissue as the IL-22 receptor is exclusively expressed on mesenchymal cells. The effect of IL-22 on enterocytes can be protective in colitis whereas it contributes to keratinocyte hyperplasia in psoriasis models. Considering the prototypical stromal alterations in SpA, it will be important to determine which innate IL-17-expressing cells can also produce IL-22 [8].

\section{Implications for targeted therapies}

The previously mentioned issues may have direct relevance for targeted therapies. If innate IL-17-expressing cells produce other IL-23-dependent pathogenic factors, would IL-23 targeting then be more useful than an antiIL-17A monoclonal antibody in SpA [5]? Or, in contrast, would it be wiser to target selectively IL-17 without impairing IL-22 production as suggested by some colitis models? Could we imagine trying to target a specific pathogenic IL-17-producing cell population - for example, using imatinib to deplete c-kit-positive mast cells and innate lymphoid cells - rather than the cytokines they produce in order to leave the protective IL-17 production untouched [11]? It is mainly in the context of selective therapeutic targeting that the work of Appel and colleagues set a first, but crucial, step in characterisation of the phenotype, developmental and transcriptional requirements, and function of innate IL-17-producing cells in SpA.

Abbreviations

IL, interleukin; SpA, spondyloarthritis; Th, T-helper type.
Competing interests

The authors declare that they have no competing interests.

Published: 24 June 2011

References

1. Appel H, Maier R, Wu P, Scheer R, Hempfing A, Kayser R, Thiel A, Radbruch A, Loddenkemper C, Sieper J: Analysis of interleukin- $17^{+}$cells in facet joints of patients with spondyloarthritis suggests that the innate immune pathway might be of greater relevance than the Th17 mediated adaptive immune response. Arthritis Res Ther 2011, 13:R95.

2. Di Meglio P, Di Cesare A, Laggner U, Chu CC, Napolitano L, Villanova F, Tosi I, Capon F, Trembath RC, Peris K, Nestle FO:The IL-23R R381Q gene variant protects against immune-mediated diseases by impairing IL-23-induced Th17 effector response in humans. PLoS One 2011, 6:e17160.

3. Sarin R, Wu X, Abraham C: Inflammatory disease protective R381Q IL23 receptor polymorphism results in decreased primary $C D 4^{+}$and $C D 8^{+}$ human T-cell functional responses. Proc Natl Acad Sci U S A 2011, 108:9560-9565.

4. DeLay ML, Turner MJ, Klenk EI, Smith JA, Sowders DP, Colbert RA: HLA-B27 misfolding and the unfolded protein response augment interleukin-23 production and are associated with Th17 activation in transgenic rats. Arthritis Rheum 2009, 60:2633-2643.

5. Baeten D, Sieper J, Emery P, Braun J, van der Heijde D, Mclnnes I, van Laar J, Landewe R, Wordsworth P, Wollenhaupt J, Kellner H, Paramarta J, Bertolino A Wright A, Hueber W: The anti-IL17A monoclonal antibody secukinumab (AIN457) showed good safety and efficacy in the treatment of active ankylosing spondylitis. Arthritis Rheum 2010, 62:2840-2841.

6. Bowness P, Ridley A, Shaw J, Chan AT, Wong-Baeza I, Fleming M, Cummings F, McMichael A, Kollnberger S: Th17 cells expressing KIR3DL2+ and responsive to HLA-B27 homodimers are increased in ankylosing spondylitis. J Immunol 2011, 186:2672-2680.

7. Uhlig HH, McKenzie BS, Hue S, Thompson C, Joyce-Shaikh B, Stepankova R, Robinson N, Buonocore S, Tlaskalova-Hogenova H, Cua DJ, Powrie F: Differential activity of IL-12 and IL-23 in mucosal and systemic innate immune pathology. Immunity 2006, 25:309-318.

8. Hueber AJ, Asquith DL, Miller AM, Reilly J, Kerr S, Leipe J, Melendez AJ, McInnes IB: Mast cell express IL-17A in rheumatoid arthritis synovium. J Immunol 2010, 184:3336-3340.

9. Lin AM, Rubin CJ, Khandpur R, Wang JY, Riblett M, Yalavarthi S, Villanueva EC, Shah P, Kaplan MJ, Bruce AT: Mast cell and neutrophils release IL-17 through extracellular trap formation in psoriasis. J Immuno/ 2011. [Epub ahead of print]

10. Geremia A, Arancibia-Cárcamo CV, Fleming MP, Rust N, Singh B, Mortensen NJ, Travis SP, Powrie F: IL-23-responsive innate lymphoid cells are increased in inflammatory bowel disease. J Exp Med 2011, 208:1127-1133.

11. Eklund KK, Remitz A, Kautiainen H, Reitamo S, Leirisalo-Repo M: Three months treatment of active spondyloarthritis with imatinib mesylate: an open-label pilot study with six patients. Rheumatology 2006, 45:1573-1575.

doi:10.1186/ar3351

Cite this article as: Yeremenko N, Baeten D: IL-17 in spondyloarthritis: is the T-party over? Arthritis Research \& Therapy 2011, 13:1 15. 